\title{
Effects of Alternating Current on Corrosion Behavior of X100 Pipeline Steel in Simulated Soil Solution
}

\author{
Yong Yang, Ming Sun, Yanlong Luo, Weiguo Zeng , Renyang He \\ China Special Equipment Inspection and Research Institute, Beijing 100029, China \\ *E-mail: 39530354@qq.com \\ doi: $10.20964 / 2021.01 .63$
}

Received: 2 September 2020 / Accepted: 7 November 2020 / Published: 30 November 2020

\begin{abstract}
Electrochemical measurements, immersion tests, and surface analysis technology were used to study the effects that alternating current (AC) has on the corrosion behavior of X100 pipeline steel in simulated alkaline and acidic soil solutions. In the both simulated soil solutions, the AC corrosion rates of X100 pipeline steel increased with an increase in the applied AC current density, but the increase in the rate of corrosion rates gradually decreased. The AC corrosion rate in the simulated acidic soil solution was higher than that in the simulated alkaline soil solution under the same AC current density. The direct current (DC) potential of X100 pipeline steel in the presence of AC current had a negative shift with respect to the natural potential. The real-time potential oscillated sinusoidally at the same frequency as the applied AC current, and the oscillation amplitude increased with an increase in AC current density. The AC corrosion products of X100 pipeline steel in the simulated acidic soil solution were less protective to the metal matrix than those in the simulated alkaline soil solution. For AC current densities greater than $100 \mathrm{~A} / \mathrm{m}^{2}$ in simulated alkaline soli solution and $200 \mathrm{~A} / \mathrm{m}^{2}$ in simulated acidic soil solutions, localized corrosion occurred, whereas general corrosion occurred under lower AC current densities.
\end{abstract}

Keywords: X100 pipeline steel, stray AC interference, AC corrosion, corrosion behavior, simulated alkaline soil solution, simulated acidic soil solution

\section{FULL TEXT}

(C) 2021 The Authors. Published by ESG (www.electrochemsci.org). This article is an open access article distributed under the terms and conditions of the Creative Commons Attribution license (http://creativecommons.org/licenses/by/4.0/). 